\begin{tabular}{|c|c|}
\hline Title & $\begin{array}{l}\text { A Note on the U se of Symmetric and A ntisymmetric Conditions in the Finite-Element A nalysis of A coustic } \\
\text { Waveguides }\end{array}$ \\
\hline Author(s) & Koshiba, M.; Suzuki, M. \\
\hline Citation & IEEE Transactions on Sonics and UItrasonics, 30(6), 370-373 \\
\hline Issue Date & $1983-11$ \\
\hline Doc URL & http:/hdl.handle.net/2115/6075 \\
\hline Rights & $\begin{array}{l}\text { C } 1983 \text { IEEE. Personal use of this material is permitted. However, permission to reprint/republish this material for } \\
\text { advertising or promotional purposes or for creating new collective works for resale or redistribution to servers or lists, } \\
\text { or to reuse any copyrighted component of this work in other works must be obtained from the IEEE. } \\
\text { IEEE, IEEE Transactions on Sonics and U Itrasonics, V olume: } 30 \text {, Issue: } 6 \text { page(s): } 370-373\end{array}$ \\
\hline Tyре & article \\
\hline File Information & ITSU30-6.pdf \\
\hline
\end{tabular}

Instructions for use 


\title{
A Note on the Use of Symmetric and Antisymmetric Conditions in the Finite-Element Analysis of Acoustic Waveguides
}

\author{
MASANORI KOSHIBA AND MICHIO SUZUKI, SENIOR MEMBER, IEEE
}

\begin{abstract}
The application of the finite-element method to the problem of wave propagation in acoustic waveguides with planes of symmetry is discussed. In particular the discussion is how to use the symmetric and antisymetric conditions on a plane of symmetry whose normal direction is not coincident with the direction of a coordinate axis.
\end{abstract}

\section{INTRODUCTION}

$I^{\prime}$ N THE finite-element analysis of acoustic waveguides with planes of symmetry, symmetric and antisymmetric conditions are often used on each plane of symmetry $[1]-[6]$. When

Manuscript received June 21, 1983.

The authors are with the Department of Electronic Engineering, Hokkaido University, Sapporo, 060, Japan. the symmetric condition is used on a plane with normal unit vector $\boldsymbol{n}$ (see Fig. 1), the particle displacement component parallel to $\boldsymbol{n}$ and the two stress components normal to $\boldsymbol{n}$ are zero on the plane. When the antisymmetric condition is used on a plane with normal unit vector $\boldsymbol{n}$, the two particle displacement components normal to $\boldsymbol{n}$ and the stress component parallel to $n$ are zero on the plane. Application of these conditions reduces the number of elements, and therefore it is possible to use computer memory more economically. In earlier finiteelement analyses [1]-[6], however, only the plane of symmetry whose normal direction is coincident with the direction of a coordinate axis is considered. In this report, we indicate how to use the symmetric and antisymmetric conditions on a 


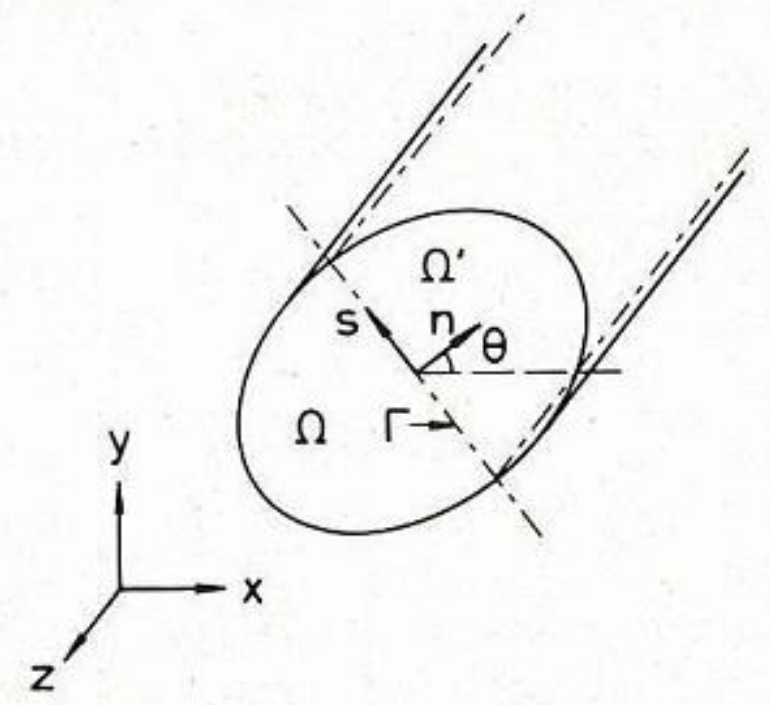

Fig. 1. Acoustic waveguide with a plane of symmetry.

plane of symmetry whose normal direction is not coincident with the direction of a coordinate axis.

\section{Development of Equations}

The coordinate system employed is shown in Fig. 1, where $z$ is taken in the direction of propagation and the unit vector $\boldsymbol{n}$ normal to the plane of symmetry $\Gamma$ lies at an angle $\theta$ from the $x$ axis in the $x y$ plane. Using the finite-element method for only the region $\Omega$, we obtain

$\left[\begin{array}{llllll}{\left[A_{x x}\right]} & {\left[A_{x y}\right]} & {\left[A_{x z}\right]} & {\left[A_{x x^{\prime}}\right]} & {\left[A_{x y^{\prime}}\right]} & {\left[A_{x z^{\prime}}\right]} \\ {\left[A_{y x}\right]} & {\left[A_{y y}\right]} & {\left[A_{y z}\right]} & {\left[A_{y x^{\prime}}\right]} & {\left[A_{y y^{\prime}}\right]} & {\left[A_{y z^{\prime}}\right]} \\ {\left[A_{z x}\right]} & {\left[A_{z y}\right]} & {\left[A_{z z}\right]} & {\left[A_{z x^{\prime}}\right]} & {\left[A_{z y^{\prime}}\right]} & {\left[A_{z z^{\prime}}\right]} \\ {\left[A_{x^{\prime} x}\right]} & {\left[A_{x^{\prime} y}\right]} & {\left[A_{x^{\prime} z}\right]} & {\left[A_{x^{\prime} x^{\prime}}\right]} & {\left[A_{x^{\prime} y^{\prime}}\right]} & {\left[A_{x^{\prime} z^{\prime}}\right]} \\ {\left[A_{y^{\prime} x}\right]} & {\left[A_{y^{\prime} y}\right]} & {\left[A_{y^{\prime} z}\right]} & {\left[A_{y^{\prime} x^{\prime}}\right]} & {\left[A_{y^{\prime} y^{\prime}}\right]} & {\left[A_{y^{\prime} z^{\prime}}\right]} \\ {\left[A_{z^{\prime} x}\right]} & {\left[A_{z^{\prime} y}\right]} & {\left[A_{z^{\prime} z}\right]} & {\left[A_{z^{\prime} x^{\prime}}\right]} & {\left[A_{z^{\prime} y^{\prime}}\right]} & {\left[A_{z^{\prime} z^{\prime}}\right]}\end{array}\right]$

$$
\left[\begin{array}{l}
\left\{u_{x}\right\} \\
\left\{u_{y}\right\} \\
\left\{u_{z}\right\} \\
\left\{u_{x^{\prime}}\right\} \\
\left\{u_{y^{\prime}}\right\} \\
\left\{u_{z^{\prime}}\right\}
\end{array}\right]=\left[\begin{array}{l}
\{0\} \\
\{0\} \\
\{0\} \\
\left\{f_{x^{\prime}}\right\} \\
\left\{f_{y^{\prime}}\right\} \\
\left\{f_{z^{\prime}}\right\}
\end{array}\right]
$$

$[A]=[K(\beta)]-\omega^{2}[M]$

$\left\{f_{i^{\prime}}\right\}=\left.\sum_{e^{\prime}} \int_{e^{\prime}}\{N\} T_{i^{\prime} n}\right|_{\Gamma} d \Gamma, \quad i^{\prime}=x^{\prime}, y^{\prime}, z^{\prime}$,

where the components of the $\left\{u_{i}\right\}$ vector are the values of the particle displacement $u_{i}$ at all nodal points in $\Omega$ except $\Gamma$, the components of the $\left\{u_{i^{\prime}}\right\}$ vector are the values of $u_{i}$ at all nodal points on $\Gamma, \omega$ is the angular frequency, $\beta$ is the phase constant in the $z$ direction, $[K(\beta)]$ and $[M]$ are the stiffness and mass matrices [1]-[6], respectively, $\left[A_{x x}\right],\left[A_{x y}\right], \cdots$, and $\left[A_{z^{\prime} z^{\prime}}\right]$ are the submatrices of $[A], T_{i^{\prime} n} \mid \Gamma$ is the stress on $\Gamma$, $\{N\}$ is the shape function [1]-[6], $\{0\}$ is the null vector, and $\Sigma_{e^{\prime}}$ extends over the elements related to $\Gamma$.

Using the symmetric condition

$$
\left\{u_{x^{\prime}}\right\}=-\tan \theta\left\{u_{y^{\prime}}\right\}, \quad\left\{f_{x^{\prime}}\right\}=\cot \theta\left\{f_{y^{\prime}}\right\}, \quad\left\{f_{z^{\prime}}\right\}=\{0\}
$$

on $\Gamma$, from (1) we obtain

$$
\begin{aligned}
& {\left[\begin{array}{lllll}
{\left[A_{x x}\right]} & {\left[A_{x y}\right]} & {\left[A_{x z}\right]} & {\left[\overline{A x y^{\prime}}\right]} & {\left[A_{x z^{\prime}}\right]} \\
{\left[A_{y x}\right]} & {\left[A_{y y}\right]} & {\left[A_{y z}\right]} & {\left[\overline{A_{y y^{\prime}}}\right]} & {\left[A_{y z^{\prime}}\right]} \\
{\left[A_{z x}\right]} & {\left[A_{z y}\right]} & {\left[A_{z z}\right]} & {\left[\overline{A_{z y^{\prime}}}\right]} & {\left[\bar{A}_{z z^{\prime}}\right]} \\
{\left[\overline{A_{y^{\prime} x}}\right]} & {\left[\overline{A_{y^{\prime} y}}\right]} & {\left[\overline{A_{y^{\prime} z}}\right]} & {\left[\overline{A_{y^{\prime} y^{\prime}}}\right]} & {\left[\overline{A_{y^{\prime} z^{\prime}}}\right]} \\
{\left[A_{z^{\prime} x}\right]} & {\left[A_{z^{\prime} y}\right]} & {\left[A_{z^{\prime} z}\right]} & {\left[\overline{A_{z^{\prime}} y^{\prime}}\right]} & {\left[A_{z^{\prime} z^{\prime}}\right]}
\end{array}\right]} \\
& {\left[\begin{array}{l}
\left\{u_{x}\right\} \\
\left\{u_{y}\right\} \\
\left\{u_{z}\right\} \\
\left\{u_{y^{\prime}}\right\} \\
\left\{u_{z^{\prime}}\right\}
\end{array}\right]=\{0\}} \\
& {\left[\bar{A}_{y^{\prime} y^{\prime}}\right]=\left[A_{y^{\prime} y^{\prime}}\right]-\tan \theta\left(\left[A_{x^{\prime} y^{\prime}}\right]+\left[A_{y^{\prime} x^{\prime}}\right]\right)} \\
& +\tan ^{2} \theta\left[A_{x^{\prime} x^{\prime}}\right] \\
& {\left[\overline{A_{j y}}\right]=\left[A_{j y^{\prime}}\right]-\tan \theta\left[A_{j x^{\prime}}\right]} \\
& {\left[\overline{A_{y^{\prime}}}\right]=\left[A_{y^{\prime} j}\right]-\tan \theta\left[A_{x^{\prime} j}\right], \quad j=x, y, z, z^{\prime} .}
\end{aligned}
$$

Using the antisymmetric condition

$$
\left\{u_{x^{\prime}}\right\}=\cot \theta\left\{u_{y^{\prime}}\right\},\left\{u_{z^{\prime}}\right\}=\{0\},\left\{f_{x^{\prime}}\right\}=-\tan \theta\left\{f_{y^{\prime}}\right\}
$$

on $\Gamma$, from (1) we obtain

$$
\begin{aligned}
& {\left[\begin{array}{llll}
{\left[A_{x x}\right]} & {\left[A_{x y}\right]} & {\left[A_{x z}\right]} & {\left[\overline{A_{x y^{\prime}}}\right.} \\
{\left[A_{y x}\right]} & {\left[A_{y y}\right]} & {\left[A_{y z}\right]} & {\left[\overline{A_{y y^{\prime}}}\right]} \\
{\left[A_{z x}\right]} & {\left[A_{z y}\right]} & {\left[A_{z z}\right]} & {\left[\overline{A_{z y^{\prime}}}\right]} \\
{\left[\overline{A_{y^{\prime} x}}\right]} & {\left[\overline{A_{y^{\prime} y}}\right]} & {\left[\overline{A_{y^{\prime} z}}\right]} & {\left[\overline{A_{y^{\prime}} y^{\prime}}\right]}
\end{array}\right]\left[\begin{array}{l}
\left\{u_{x}\right\} \\
\left\{u_{y}\right\} \\
\left\{u_{z}\right\} \\
\left\{u_{y^{\prime}}\right\}
\end{array}\right]=\{0\}} \\
& {\left[\overline{\left.A_{y^{\prime} y^{\prime}}\right]}=\left[A_{y^{\prime} y^{\prime}}\right]+\cot \theta\left(\left[A_{x^{\prime} y^{\prime}}\right]+\left[A_{y^{\prime} x^{\prime}}\right]\right)\right.} \\
& +\cot ^{2} \theta\left[A_{x^{\prime} x^{\prime}}\right] \\
& {\left[\overline{A_{j y^{\prime}}}\right]=\left[A_{j y^{\prime}}\right]+\cot \theta\left[A_{j x^{\prime}}\right]} \\
& {\left[\overline{A_{y^{\prime} j}}\right]=\left[A_{y^{\prime} j}\right]+\cot \theta\left[A_{x^{\prime} j}\right], \quad j=x, y, z \text {. }}
\end{aligned}
$$

When $\tan \theta \rightarrow \infty$ in (3) and $\cot \theta \rightarrow \infty$ in (5), $\left\{u_{y^{\prime}}\right\},\left[\bar{A}_{y^{\prime} y^{\prime}}\right]$, $\left[\overline{A_{j y}}\right]$ and $\left[\bar{A}_{y^{\prime} j}\right]$ should be replaced by $\left\{u_{x^{\prime}}\right\},\left[A_{x^{\prime} x^{\prime}}\right],\left[A_{j x^{\prime}}\right]$ and $\left[A_{x^{\prime} j}\right]$, respectively.

\section{Results}

First, let us consider an isotropic square rod with four planes of symmetry $x=0, y=0$, and $x= \pm y$, as in Fig. 2 . We subdivide one quarter or one eighth of the cross section into second-order triangular elements as shown in Fig. 3. Table I gives the numerical results for the normalized phase velocities $v /\left(c_{44} / \rho\right)^{1 / 2}$ for the fundamental branches of the longitudinal $(L)$, first screw $\left(S^{(1)}\right)$, torsional $(T)$, and second screw $\left(S^{(2)}\right)$ modes in a square rod with Poisson's ratio $\sigma=0.3$, where $v=\omega / \beta, c_{44}$ is the stiffness constant and $\rho$ is the mass density. The fields of the $L$ 


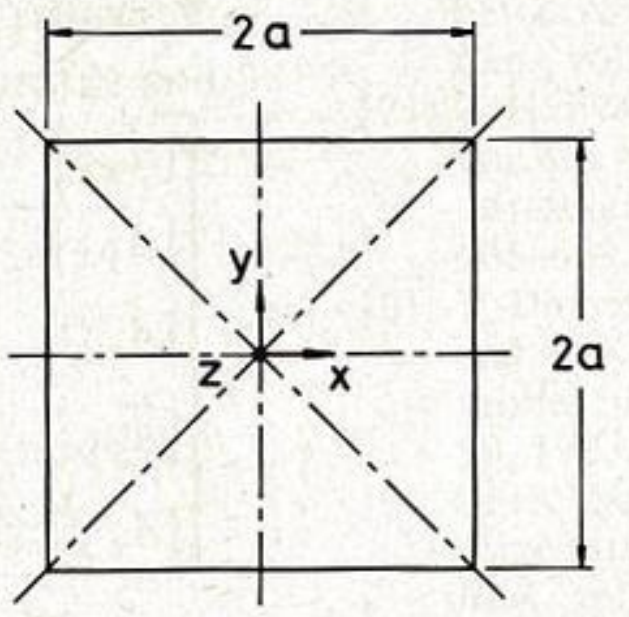

Fig. 2. Square rod.

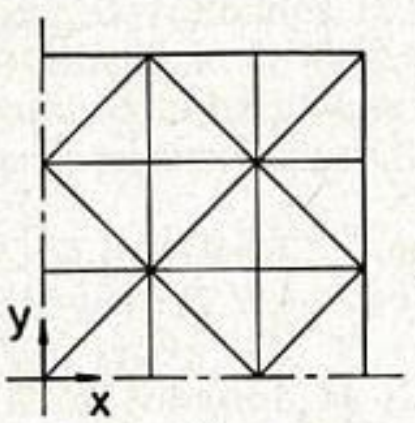

(a)

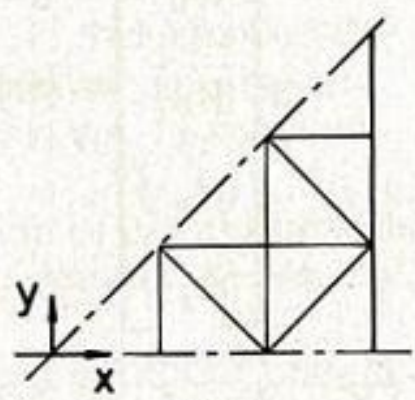

(b)

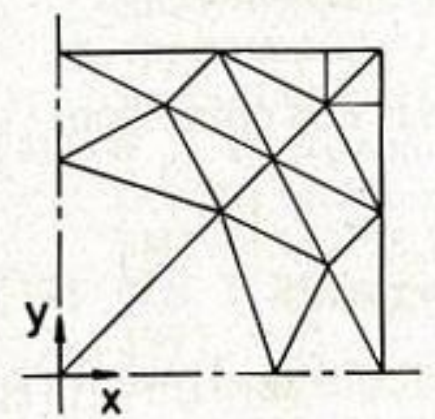

(c)

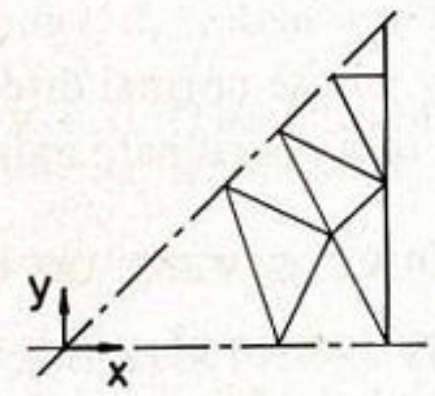

(d)

Fig. 3. Finite-element divisions of a square rod.

TABLE I

Normalized Phase Velocities as a Function of $\beta a$ for an Isotropic Square Rod $(\sigma=0.3)$

\begin{tabular}{|c|c|c|c|c|c|c|}
\hline \multirow{2}{*}{ Mode } & \multirow{2}{*}{$\mathrm{Ba}$} & \multirow{2}{*}{$\begin{array}{l}\text { Variational } \\
\text { method[7] }\end{array}$} & \multirow{2}{*}{$\begin{array}{l}\text { Collocation } \\
\text { method[8] }\end{array}$} & \multirow{2}{*}{$\begin{array}{l}\text { Mode- } \\
\text { matching } \\
\text { method[9] }\end{array}$} & \multicolumn{2}{|c|}{ Finite-element method } \\
\hline & & & & & Fig. $3(a) \&(b)$ & Fig. $3(\mathrm{c}) \&(\mathrm{~d})$ \\
\hline \multirow{5}{*}{$L_{1}$} & 1 & 1.5511 & 1.5512 & 1.5512 & 1.5512 & 1.5512 \\
\hline & 3 & 1.069 & 1.0688 & 1.0688 & 1.0690 & 1.0591 \\
\hline & 5 & 0.962 & 0.962 & 0.9618 & 0.9632 & 0.9624 \\
\hline & 10 & 0.936 & 0.934 & 0.9342 & 0.9445 & 0.9384 \\
\hline & 14 & 0.939 & 0.931 & 0.9313 & 0.9519 & 0.9404 \\
\hline \multirow{5}{*}{$s_{1}^{(1)}$} & 1 & 2.165 & 2.1646 & 2.1646 & 2.1650 & 2.1655 \\
\hline & 3 & 0.9761 & 0.9759 & 0.9759 & 0.9764 & 0.9763 \\
\hline & 5 & 0.9090 & 0.908 & 0.9081 & 0.9108 & 0.9089 \\
\hline & 10 & 0.9121 & 0.903 & 0.9035 & 0.9208 & 0.9074 \\
\hline & 14 & 0.9234 & & 0.9040 & 0.9368 & 0.9128 \\
\hline \multirow{5}{*}{$T_{1}$} & 1. & 0.9178 & 0.9182 & 0.9180 & 0.9185 & 0.9184 \\
\hline & 3 & 0.9134 & & 0.9153 & 0.9166 & 0.9159 \\
\hline & 5 & 0.9054 & & 0.9112 & 0.9151 & 0.9123 \\
\hline & 10 & 0.9018 & 0.905 & 0.9053 & 0.9245 & 0.9095 \\
\hline & 14 & 0.9185 & 0.905 & 0.9045 & 0.9386 & 0.9133 \\
\hline \multirow{5}{*}{$s_{1}^{(2)}$} & 1 & 1.969 & 1.9680 & 1.9685 & 1.9692 & 1.9700 \\
\hline & 3 & 1.068 & 1.0677 & 1.0678 & 1.0686 & 1.0684 \\
\hline & 5 & 0.990 & & & 0.9922 & 0.9911 \\
\hline & 10 & 0.953 & 0.952 & 0.9522 & 0.9626 & 0.9561 \\
\hline & 14 & 0.952 & 0.942 & 0.9424 & 0.9627 & 0.9503 \\
\hline
\end{tabular}

and $S^{(1)}$ modes satisfy the symmetric conditions on $x=0$ and $y=0$. The fields of the $T$ and $S^{(2)}$ modes satisfy the antisymmetric conditions on $x=0$ and $y=0$. The fields of the $L$ and $S^{(2)}$ modes satisfy the symmetric conditions on $x= \pm y$. The fields of the $T$ and $S^{(1)}$ modes satisfy the antisymmetric conditions on $x= \pm y$. In Table I the results of the variational method [7], the collocation method [8], and the modematching method [9] are also presented. The results of Figs. 3(b) and (d) are identical to those of Figs. 3(a) and (c), respectively. This fact proves the validity of (3) and (5).
Next, let us consider anisotropic square rods with four planes of symmetry $x=0, y=0$, and $x= \pm y$. We subdivide one eighth of the cross section into second-order triangular elements as in Fig. 3(d).

The normalized phase velocities for the fundamental branches of the $L, S^{(1)}, T$, and $S^{(2)}$ modes are presented in Tables II, III, and IV for tetragonal $\left(\mathrm{NiSO}_{4}\right)$, hexagonal (zinc), and cubic (copper) materials [10], respectively. For $\mathrm{NiSO}_{4}$ and copper the $L_{1}$ and $S_{1}{ }^{(1)}$ branches intersect. The results that Nigro [10] has identified with the first two branches of the $L$ mode 
TABLE II

Normalized Phase Velocities as a Function of $\beta a$ for a Tetragonal Square Rod $\left(\mathrm{NiSO}_{4}\right)$

\begin{tabular}{r|c|c|c|c|c|c|c|c}
\hline \multirow{3}{*}{ Ba } & \multicolumn{5}{|c|}{ Finite-element method } & \multicolumn{2}{c|}{ Variational method[10] } & \multicolumn{2}{c}{ Variational method[13] } \\
\cline { 2 - 8 } & $L_{1}$ & $S_{1}^{(1)}$ & $T_{1}$ & $S_{1}^{(2)}$ & Branch 1 & Branch 2 & $T_{1}$ & $S_{1}^{(2)}$ \\
\hline \multirow{2}{*}{0.1} & 1.5879 & 13.8540 & 0.9187 & 22.1852 & 1.585 & 13.84 & 0.919 & \\
0.5 & 1.5878 & 2.7767 & 0.9179 & 4.3769 & 1.585 & 2.77 & 0.918 & 4.378 \\
1.0 & 1.5875 & 1.4290 & 0.9153 & 2.2470 & 1.427 & 1.58 & 0.916 & 2.251 \\
2.0 & 1.5100 & 0.9022 & 0.9045 & 1.3368 & 0.901 & 1.25 & 0.904 & 1.339 \\
3.0 & 1.1878 & 0.8324 & 0.8876 & 1.1148 & 0.831 & 1.07 & 0.887 & 1.118 \\
4.0 & 1.0697 & 0.8295 & 0.8708 & 1.0340 & 0.828 & 1.00 & 0.871 & 1.037 \\
5.0 & 1.0178 & 0.8362 & 0.8596 & 0.9983 & 0.84 & 0.97 & 0.859 & 1.000 \\
6.0 & 0.9916 & 0.8424 & 0.8540 & 0.9804 & 0.84 & 0.95 & 0.854 & 0.981 \\
7.0 & 0.9769 & 0.8466 & 0.8517 & 0.9706 & 0.85 & 0.94 & 0.852 & 0.972 \\
8.0 & 0.9677 & 0.8494 & 0.8513 & 0.9648 & 0.86 & 0.94 & 0.852 & 0.965 \\
9.0 & 0.9612 & 0.8514 & 0.8519 & 0.9613 & 0.86 & 0.94 & & \\
10.0 & 0.9558 & 0.8531 & 0.8530 & 0.9590 & & & & \\
\hline
\end{tabular}

TABLE III

Normalized Phase Velocities as a Function of $\beta a$ for a Hexagonal Square Rod (Znc)

\begin{tabular}{r|c|c|c|c|c|c|c|c}
\hline \multirow{2}{*}{ Ba } & \multicolumn{5}{|c|}{ Finite-element method } & Variational method[10] & \multicolumn{2}{c}{ Variational method[13] } \\
\cline { 2 - 8 } & $L_{1}$ & $S_{1}^{(1)}$ & $T_{1}$ & $S_{1}^{(2)}$ & Branch 1 & Branch 2 & $T_{1}$ & $S_{1}^{(2)}$ \\
\hline \multirow{2}{*}{0.1} & 0.9536 & 27.8624 & 0.9187 & 22.1878 & 0.954 & 27.84 & 0.919 & \\
0.5 & 0.9503 & 5.3884 & 0.9182 & 4.3262 & 0.951 & 5.39 & 0.919 & 4.325 \\
1.0 & 0.9389 & 2.5278 & 0.9166 & 2.1231 & 0.939 & 2.53 & 0.916 & 2.124 \\
2.0 & 0.8790 & 1.1931 & 0.9095 & 1.1560 & 0.879 & 1.19 & 0.909 & 1.157 \\
3.0 & 0.7893 & 0.8679 & 0.8958 & 0.9418 & 0.790 & 0.87 & 0.895 & 0.946 \\
4.0 & 0.7500 & 0.7800 & 0.8736 & 0.8837 & & & 0.873 & 0.885 \\
5.0 & 0.7484 & 0.7632 & 0.8451 & 0.8655 & 0.749 & 0.76 & 0.844 & 0.867 \\
6.0 & 0.7591 & 0.7674 & 0.8190 & 0.8373 & 0.76 & 0.77 & 0.817 & 0.837 \\
7.0 & 0.7708 & 0.7761 & 0.8017 & 0.8098 & 0.77 & 0.78 & 0.800 & 0.813 \\
8.0 & 0.7790 & 0.7832 & 0.7927 & 0.7959 & 0.78 & 0.79 & 0.793 & 0.798 \\
9.0 & 0.7824 & 0.7866 & 0.7893 & 0.7905 & 0.78 & 0.79 & & \\
10.0 & 0.7829 & 0.7871 & 0.7890 & 0.7893 & & & & \\
\hline
\end{tabular}

TABLE IV

Normalized Phase Velocities as a Function of $\beta a$ for a Cubic Square Rod (Copper)

\begin{tabular}{r|c|c|c|c|c|c|c|c}
\hline \multirow{2}{*}{ Ba } & \multicolumn{5}{|c|}{ Finite-element method } & \multicolumn{2}{c|}{ Variational method[10] } & \multicolumn{2}{c}{ Variationa] method[13] } \\
\cline { 2 - 8 } & $L_{1}$ & $S_{1}^{(1)}$ & $T_{1}$ & $S_{1}^{(2)}$ & Branch 1 & Branch 2 & $T_{1}$ & $S_{1}^{(2)}$ \\
\hline \multirow{2}{*}{0.1} & 1.0016 & 13.2441 & 0.9187 & 19.4126 & 1.001 & 13.23 & 0.918 & \\
0.5 & 0.9874 & 2.6441 & 0.9168 & 3.7881 & 0.987 & 2.64 & 0.917 & 3.787 \\
1.0 & 0.9392 & 1.3039 & 0.9105 & 1.8649 & 0.939 & 1.30 & 0.910 & 1.864 \\
2.0 & 0.7667 & 0.7121 & 0.8781 & 1.0560 & 0.711 & 0.77 & 0.877 & 1.056 \\
3.0 & 0.6954 & 0.6536 & 0.8102 & 0.8996 & 0.653 & 10.70 & 0.808 & 0.899 \\
4.0 & 0.7147 & 0.6845 & 0.7492 & 0.8346 & 0.68 & 0.71 & 0.747 & 0.831 \\
5.0 & 0.7442 & 0.7126 & 0.7243 & 0.7824 & 0.71 & 0.74 & 0.723 & 0.782 \\
6.0 & 0.7413 & 0.7143 & 0.7210 & 0.7648 & 0.71 & 0.74 & 0.721 & 0.765 \\
7.0 & 0.7298 & 0.7090 & 0.7241 & 0.7636 & 0.71 & 0.72 & 0.724 & 0.765 \\
8.0 & 0.7306 & 0.7115 & 0.7258 & 0.7638 & 0.71 & 0.73 & 0.724 & 0.765 \\
9.0 & 0.7373 & 0.7175 & 0.7255 & 0.7599 & 0.72 & 0.74 & & \\
10.0 & 0.7437 & 0.7225 & 0.7254 & 0.7560 & & & & \\
\hline
\end{tabular}


are also shown in Tables II-IV (branch 1 and branch 2), and we see that for $\mathrm{NiSO}_{4}$ and copper the branches 1 and 2 must be reidentified as in Tables II and IV [11]. Nigro's reidentified results are in good agreement with the present results for the $L_{1}$ and $S_{1}{ }^{(1)}$ branches. Our results for the $T_{1}$ and $S_{1}{ }^{(2)}$ branches agree well with those of Nigro and O'Malley [12], [13].

\section{ACKNOWLEDGMENT}

The authors wish to thank M. Okada for his assistance in numerical computations. They are greatly indebted to the reviewers for their helpful suggestions.

\section{REFERENCES}

[1] R. Burridge and F. J. Sabina, "Theoretical computations on ridge acoustic surface waves using the finite-element method," Electron. Lett., vol. 7, pp. 720-722, 1971.

[2] G. O. Stone, "Coupling matrices for high-order finite-element analysis of acoustic-wave propagation," Electron. Lett., vol. 8, pp. 466-468, 1972.

[3] P. E. Lagasse, "Higher-order finite-element analysis of topographic guides supporting elastic surface waves," J. Acoust. Soc. Amer., vol. 53, pp. 1116-1122, 1973.

[4] B. Aalami, "Waves in prismatic guides of arbitrary cross section," J. Appl. Mech., vol. 40-E, pp. 1067-1072, 1973.
[5] M. Koshiba, T. Tanifuji, and M. Suzuki, "Acoustic wave propagation in rods of rectangular cross section," Trans. Inst. Electron. Commun. Eng. Japan, vol. 57-B, pp. 734-741, 1974.

[6] A. J. Jennings and G. K. Cambrell, "Refined finite-element analysis of a clad fiber acoustic waveguide," IEEE Trans. Sonics Ultrason., vol. SU-29, pp. 239-248, 1982.

[7] N. J. Nigro, "Steady-state wave propagation in infinite bars of noncircular cross section," J. Acoust. Soc. Amer., vol. 40, pp. 1501-1508, 1966.

[8] W. B. Fraser, "Stress wave propagation in rectangular bars," Int. J. Solids Structures, vol. 5, pp. 379-397, 1969.

[9] T. Miyamoto and K. Yasuura, "Numerical analysis on isotropic elastic waveguides by mode-matching method-II. Particle velocities and dispersion characteristics in rods of rectangular cross section," IEEE Trans. Sonics Ultrason., vol. SU-24, pp. 369-375, 1977.

[10] N. J. Nigro, "Wave propagation in anisotropic bars of rectangular cross section. Part. I. Longitudinal wave propagation," J. Acoust. Soc. Amer., vol. 43, pp. 958-965, 1968.

[11] N. J. Nigro and P. Huang, "Method for determining the elastic constants of solids," J. Acoust. Soc. Amer., vol. 54, pp. 1004$1007,1973$.

[12] N. J. Nigro and P. A. O'Malley, "Wave propagation in anisotropic bars of rectangular cross section. III," J. Acoust. Soc. Amer., vol. 55, pp. 718-723, 1974.

[13] P. A. O'Malley, "The application of the Ritz method to steady state, torsional vibration of anisotropic bars of rectangular cross section," M. S. thesis, Marquette University, Milwaukee, WI, 1969. 